\title{
Palliative care for patients with advanced fibrotic lung disease: a randomised controlled phase II and feasibility trial of a community case conference intervention
}

\author{
Sabrina Bajwah, ${ }^{1,2}$ Joy R Ross, ${ }^{1,3}$ Athol U Wells, ${ }^{3,4}$ Kabir Mohammed, $^{5}$ \\ Christina Oyebode, ${ }^{1}$ Surinder S Birring, ${ }^{6}$ Amit S Patel, ${ }^{6}$ Jonathan Koffman, ${ }^{2}$ \\ Irene J Higginson, ${ }^{2}$ Julia Riley ${ }^{1,3}$
}

- Additional material is published online only. To view please visit the journal online (http://dx.doi.org/10.1136/ thoraxjn-2014-206583)

'Department of Palliative Medicine, Royal Marsden and Royal Brompton NHS Foundation Trusts, London, UK ${ }^{2}$ Department of Palliative Care, King's College London, Cicely Saunders Institute, Policy \& Rehabilitation, London, UK ${ }^{3}$ National Heart and Lung Institute, Imperial College, London, UK

${ }^{4}$ Department of Respiratory Medicine, Royal Brompton NHS Foundation Trust, London, UK ${ }^{5}$ Department of Statistics, Royal Marsden NHS Foundation Trust, London, UK

${ }^{6}$ Division of Asthma, Allergy and Lung Biology, King's College London, London, UK

Correspondence to Dr Sabrina Bajwah, Department of Palliative Care, Policy \& Rehabilitation, Bessemer Rd, Cicely Saunders Institute, London SE5 9PJ, UK. sabrina.bajwah@kcl.ac.uk

Received 19 November 2014 Revised 12 May 2015 Accepted 18 May 2015 Published Online First 23 June 2015

\section{ABSTRACT}

Background Those affected by advanced fibrotic interstitial lung diseases (ILDs) have considerable unmet symptom and psychological needs. Case conferencing has been proposed to address these issues, but requires evaluation.

Aim To obtain preliminary information on the impact of a case conference intervention delivered in the home (Hospital2Home) on palliative care concerns of patients and their carers, and to evaluate feasibility and acceptability.

Methods Hospital2Home was trialled at a specialist centre using a Phase II fast-track randomised controlled trial with qualitative interviews. The primary outcome for effect was mean change from baseline of Palliative Care Outcome Scale (POS) (a measure of symptoms and concerns) at 4 weeks. Secondary outcomes included symptom control, quality of life, consent and recruitment rates and percentage of patients in the fast-track group receiving case conferences within 14 days.

Results 53 patients were recruited (26 fast-track, 27 controls). Mean (SD) POS scores at 4 weeks were -5.7 (7.5) fast-track vs -0.4 (8.0) control, (mean change difference between the two arms was $-5.3(95 \% \mathrm{Cl}$ -9.8 to -0.7$)$ independent t test $p=0.02)$; effect size $(95 \% \mathrm{Cl})-0.7(-1.2$ to -0.1$)$. The secondary outcomes of quality of life, anxiety and depression were superior in the fast-track arm, and none were worse. Qualitative findings corroborate these data. Recruitment was successful and 53/67 (79\%) of eligible patients consented. $6 / 25$ (24\%) had case conferences within 14 days.

Conclusions Community case conferences improve palliative symptoms and quality of life after 4 weeks. Hospital2Home for the most part is both feasible and acceptable. It now requires further testing in multicentre trials.

Trial registration number NCT01450644

\section{INTRODUCTION}

CrossMark

To cite: Bajwah S, Ross JR, Wells AU, et al. Thorax 2015;70:830-839.
Patients with idiopathic fibrotic lung diseases include a large patient subgroup with idiopathic pulmonary fibrosis (IPF), or with alternative diagnoses but an IPF-like outcome. ${ }^{1}$ These patients experience substantial unmet symptom and psychosocial concerns that profoundly impact on patients'

\section{Key messages}

What is the key question?

- Could a palliative case conference intervention improve palliative care concerns and be feasible in advanced fibrotic interstitial lung disease (ILD)?

What is the bottom line?

- The case conference intervention may improve patients' and carers' palliative care concerns while being feasible and acceptable.

\section{Why read on?}

- People living with advanced fibrotic ILD experience high levels of unmet palliative care concerns and this work shows that evidence based palliative interventions such as the case conference can be developed and robustly evaluated to improve and direct care.

and carers' lives. ${ }^{2-4}$ In addition, poor communication and coordination of care, with little or no discussion surrounding important end-of-life preferences has been reported. ${ }^{4}$

Recent UK Government legislation promotes better integration of care to improve patient experience and outcomes, providing better continuity of individualised care at the end of life. ${ }^{5}{ }^{6}$ Targeted organisation of care, improved communication and cooperation between disciplines across multiple healthcare settings is required to enable appropriate delivery of palliative care. ${ }^{7}$ Case conferencing at the interface between primary and specialist care may deliver individualised holistic care while addressing important unmet palliative care concerns. $^{8-10}$ Research into case conferences in the non-malignant respiratory setting or centred on the patients' and carers' concerns are absent. In addition, there is a paucity of research developing complex interventions among those with fibrotic lung disease aimed at improving their symptoms and quality of life. ${ }^{11}$

We conducted a phase II feasibility trial of a case conference intervention (Hospital2Home) to obtain 
preliminary information in what ways Hospital2Home influences the palliative care concerns of patients with advanced fibrotic interstitial lung disease (ILD) and their carers, and to evaluate the feasibility and acceptability of the intervention in this group.

\section{METHODS}

\section{Study design}

A fast-track (wait list) randomised controlled trial with embedded qualitative interviews were conducted as part of a larger project developing and evaluating Hospital2Home using the Medical Research Council's guidance for developing and evaluating complex interventions. ${ }^{12}$ After consent and baseline interview, patients were randomised to fast-track or waiting list groups. For fast-track patients, a Hospital2Home nurse organised a case conference as soon as possible. Waiting list patients were referred for the case conference 4 weeks after randomisation. During the course of the trial, it became apparent that it was extremely difficult to get the case conference for those patients who were randomised to the fast-track group organised within 1 week and sometimes the waiting list group's case conference at exactly 4 weeks. An amendment allowed flexibility in the time points of the case conferences and the assessments. Treatment allocation (fast-track/waiting list group) was by computer generated random permuted blocks (by the Institute of Cancer Research) with stratification dependent on severity of patient Palliative Care Outcome Scale (POS) at baseline (patients with a POS score $\geq 28$ were classed as severe).

\section{Subjects}

Patients with a clinical diagnosis of advanced idiopathic fibrotic lung disease (IPF by American Thoracic Society/European Respiratory Society criteria ${ }^{13}$ or fibrotic non-specific interstitial pneumonia) were recruited from the inpatient and outpatient settings in a specialist ILD centre (Royal Brompton Hospital, London). Patients included were considered to have end stage disease as judged by either high resolution CT or composite physiologic index scores. Total disease on $\mathrm{CT}$ was categorised as limited $(<40 \%)$, extensive $(>60 \%)$ or indeterminate $(40-60 \%)$. The proportion of honeycombing was recorded as limited $(<15 \%)$, extensive $(>35 \%)$ or indeterminate $(15-35 \%)$. Disease was classed as extensive if (1) Extensive disease $(>60 \%)$ or honeycombing (>35\%) on CT or (2) Composite Physiological Index $>50$. Previous work done by Wells $e t a l^{14}$ has shown a separation in survival between limited $(\mathrm{n}=36)$ and extensive $(\mathrm{n}=100)$ disease using this classification ( $\mathrm{HR}=5.2$ (CI 3.3 to 8.1) $\mathrm{p}<0.0005$ ); the latter group (extensive disease) had a $10 \%$ survival at 2 years. A subsequent amendment allowed recruitment of patients considered to have end-stage disease clinically (based on clinical status, oxygen requirements and, in some cases, the presence of severe pulmonary hypertension) who were too unwell to complete pulmonary function tests.

To be included patients and carers had to be $>18$ years old, possess sufficient mental capacity and be able to complete questionnaires in English. Where possible, patient and carer dyads were recruited.

\section{Intervention}

All patients received best standard care throughout the study: Patients remained under ILD specialist care for the full duration of the study. This included receiving input from ILD physicians, ILD clinical nurse specialist, occupational therapist, physiotherapist and oxygen assessment and treatment services. In addition, all patients were able to access inpatient ILD treatment as needed. Referrals to community health professionals (as deemed necessary by the ILD team) continued throughout the study. These could include referrals to community nursing (such as community matron or district nurses), respiratory services and community palliative care teams. The Hospital2Home intervention was delivered alongside best standard care (box 1). The fast-track group received the intervention after 1 week, the waiting list group after 4 weeks.

\section{Primary outcome}

The primary outcome was POS. ${ }^{15}$ POS was developed for patients with advanced cancer and includes aspects about pain and symptom control, patient and family psychosocial needs, and communication and information needs. ${ }^{15}$ The POS contains eight questions on anxiety, patient and informal caregiver concerns, and practical needs, each rated $0-4$. The overall profile score is the sum of the scores from each of the 10 questions and can range from 0 to 40 . Symptoms identified in preliminary work were added to question 2- 'Over the past 3 days, have other symptoms eg. having a cough, shortness of breath, fatigue or insomnia been affecting how you feel?'. This adapted POS was used to provide an assessment of change in palliative care needs (including symptom control).

\section{Secondary outcomes}

Secondary outcomes included changes in symptom control and quality of life measures (table 1). Details of each secondary measure can be located online in online supplementary appendix 1

Primary and secondary outcome data were collected by postal questionnaire at baseline in both groups. Subsequent time points were 4 weeks and 8 weeks after receiving the intervention in the fast-track group and just before receiving the intervention and 4 weeks after receiving the intervention in the waiting list group. Demographic information was also recorded. Qualitative interviews were conducted after completion of the trial. The topic guide used is depicted in figure 1 .

\section{Feasibility and acceptability}

A priori criteria for trial feasibility were:

- Consent rate of at least 25\%;

- Recruitment of 52 patients;

- $80 \%$ of patients in the fast-track group received their case conference within 14 days of randomisation.

The qualitative interviews were used in the post-trial evaluation to assess acceptability.

\section{Sample size, randomisation and data analysis}

Fifty-two patients were needed to enable estimation of change in POS between baseline and 4 weeks with accurate precision (assuming a SD of 2, a 95\% CI for the difference between the fast-track and waiting list groups would be 2.2 units wide, ie, mean difference \pm 1.1 units). Anticipated recruitment for qualitative work was 15 (5 patients, 5 carers and 5 health professionals).

We planned an intention-to-treat analysis. The differences in the change in POS scores (baseline to 4 weeks) between the fasttrack and waiting list groups were compared using an Independent sample $t$ test. For all secondary outcome measures descriptive methods were used to report the results in the groups using mean change scores with $\mathrm{SD}$ from baseline to week 4 and effect size at week 4 . Only patients with week 4 data were included in change analysis. All quantitative data were analysed using Statistical Package for the Social Sciences (Version 21, IBM, Chicago, Illinois, USA). 


\section{Box 1 Hospital2Home intervention}

\section{Aims and rationale}

The intervention aimed to provide a quality comprehensive palliative care assessment and streamlining of transfer of data between specialist and community settings improving coordination of care and communication while codifying responsibility for the patient, carer and health professionals. In the UK, a case conference model of care (Hospital2Home) has been used in patients with cancer in the acute oncology setting. The Hospital2Home model of care is unique as it has the advantages of a case conference (multiprofessional and holistic) and a care plan (care individualised to each patient and carer). The fibrotic interstitial lung disease Hospital2Home model was

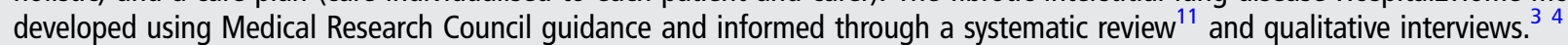

\section{Personnel}

Provider: A palliative care specialist nurse delivered the intervention. The nurse had received training on delivery of the intervention from specialist nurses delivering the cancer Hospital2Home intervention.

Supervision: Clinical supervision was provided to assist in identifying and advising on strategies to address problems compromising effective management of the palliative care concerns of these patients and carers. The supervisors met with the nurse approximately weekly and provided additional telephone support as needed.

Attendees: The patient, their carer, Hospital2Home nurse, general practitioner, community matron/district nurse, respiratory nurse and community palliative care nurse (and any other health or social care professional involved in their care or identified as important by the patient) were invited to attend. All patients in the waiting list group who received the case conference had a carer who was present at the case conference. However only 19/25 patients in the fast-track group had carers and only 18 of these attended the case conference. There was consistent representation from community nursing and palliative care teams. However, less than $50 \%$ of general practitioners attended the case conferences.

\section{Format}

Setting: Case conferences were conducted in the community at a place chosen by the patient (all patients chose their home) Mean (SD) time in minutes taken to organise the case conference for fast-track group 204 (78) range 60-360 and for waiting list group 219 (86) range 60-390.

Schedule and duration: 25 patients in the fast-track group and 24 patients in the waiting list group received the case conference. The Hospital2Home nurse contacted patients after randomisation. For patients in the fast-track group where possible, the case conference was organised within 1 week (6/25 (24\%) had case conference within 14 days, median 23 days, range 12-51). For patients in the waiting list group, this was organised for 4 weeks time (median 40 days, range 7-100). The median length of case conference was $90 \mathrm{~min}$ in both groups with a range of 60-120 min in the fast-track group and 60-150 min in the waiting list group. The Hospital2 Home nurse followed up the case conferences in each group with the patient/carer via telephone at 2-week, 1 month and 2-month intervals. Patients and carers were also able to contact the nurse directly as needed for the length of the study. Contacts in addition to scheduled follow-up were mean (SD) 49 (78) min, range 0-300 min for the fast-track group and 35 (48) min, range 0-120 min for the waiting list group.

\section{Content}

Prior to the case conference, the Hospital2Home nurse telephoned the patient and carer to identify what their current palliative care concerns were and what they hoped to achieve from the case conference. This included identifying whether patients wished to discuss the sensitive matter of disease progression and planning for the future. During the case conference, which was led by the Hospital2Home nurse, current and anticipated care palliative care concerns were discussed. This included physical, psychological, social and spiritual concerns. In addition, where appropriate, end-of-life preferences were discussed. Preferred place of care-where the patient wished to be cared for in the last few weeks of life was discussed in $17(68 \%)$ of fast-track and $23(96 \%)$ of waiting list case conferences. For $13(52 \%)$ of the fast-track group and $23(96 \%)$ of the waiting list group this was home. Preferred place of deathwhere the patient wished to die was discussed at $11(28 \%)$ of fast-track and $10(42 \%)$ of waiting list case conferences. Reasons for non-discussion for preferred place of care and death were patient choice.

An action plan was agreed upon for each concern discussed at the case conference and a responsible healthcare professional allocated for each item. Following the case conference the Hospital2Home nurse, with contact details of each health professional, drafted an individualised care plan. The individualised care plan was then communicated to the patient and carer, the ILD specialist team, the general practitioner, all attendees at the case conference and any other health professional identified by the patient as involved in their care. The Hospital2Home nurse would check with the patient/carer at the follow-up phone calls that all action points on the care plan had been completed by the allocated health professional. The Hospital2Home nurse aimed to resolve any issues by liaising with the relevant community health professionals.

Delivery

Delivery methods: A collaborative problem solving approach was used whereby the patient and health professionals set agreed goals and jointly developed strategies to achieve them (with advice from the supervisors as needed).

Standardisation: Pro forma were used to standardise delivery and general content of the case conference and follow-up phone calls and to document issues arising from individual discussions, agreed goals, and difficulties and points for action or discussion at supervisory meetings. Symptom control management was guided by evidence based guidelines developed during preliminary work (available on request from corresponding author).

All qualitative interviews were digitally recorded and transferred verbatim onto a secure transcription database. Analysis was conducted using a constant comparison approach ${ }^{23}$ within
Framework analysis as described by Ritchie and Spencer. ${ }^{24}$ Qualitative analysis was facilitated by NVivo V.9. Efforts to maximise analytical rigour included dual coding of a sample 
Table 1 Outcome measures used

\begin{tabular}{|c|c|}
\hline $\begin{array}{l}\text { Baseline characteristicl } \\
\text { outcome }\end{array}$ & Instrument/measure \\
\hline \multicolumn{2}{|l|}{ Patient } \\
\hline Patient palliative care needs & $\begin{array}{l}\text { Palliative Care Outcome Scale }{ }^{15} \text { with additional } \\
\text { questions for breathlessness, cough, fatigue, } \\
\text { insomnia (to be completed by patient and } \\
\text { carer) }\end{array}$ \\
\hline $\begin{array}{l}\text { Patient breathlessness at } \\
\text { best/worst }\end{array}$ & D12 scale ${ }^{16}$ \\
\hline Patient quality of life & $\begin{array}{l}\text { Kings Brief Interstitial Lung Disease } \\
\text { questionnaire }{ }^{17} \text { and SGRQ }{ }^{18 *}\end{array}$ \\
\hline Patient functional ability & Medical Research Council breathlessness scale ${ }^{19}$ \\
\hline Patient anxiety & Hospital Anxiety and Depression Scale ${ }^{20}$ \\
\hline Patient use of other services & Service use questions \\
\hline \multicolumn{2}{|c|}{ Preferred place of care and death } \\
\hline \multicolumn{2}{|c|}{ Carer } \\
\hline Carer quality of life & Caregiver Quality of Life Index ${ }^{21}$ \\
\hline Carer anxiety & Hospital Anxiety and Depression scale ${ }^{20}$ \\
\hline $\begin{array}{l}\text { Carer's assessment of } \\
\text { patient's use of services }\end{array}$ & Service use questions \\
\hline Carer burden & Zarit Burden Inventory ${ }^{22}$ \\
\hline
\end{tabular}

selection of the interview transcripts and attention of deviant or non-confirmatory cases.

\section{RESULTS}

Patients were recruited October 2011-October 2013 and followed up until December 2013 (when the final patients recruited had completed 8 weeks in the trial) (figure 2).

\section{Baseline measures}

Baseline demographic and clinical characteristics for patients and carers are presented in table 2 .

All analyses were by originally assigned groups.

\section{Primary end point}

There was a significantly greater reduction in total POS between baseline and week 4 for the fast-track group than in the waiting list group; mean change (SD) -5.7 (7.5) vs $-0.4(8.0)$, respectively. The mean change difference between the two arms was $-5.3(95 \% \mathrm{CI}-9.8$ to -0.7$)$ independent $\mathrm{t}$ test $\mathrm{p}=0.02$; effect size $(95 \% \mathrm{CI})$ of $-0.7(-1.2$ to -0.1$)$ (figure 3$)$.

\section{Secondary outcomes}

\section{Patient}

For the fast-track group, initial improvements in POS score, King's Brief Interstitial Lung Disease (KBILD) questionnaire,

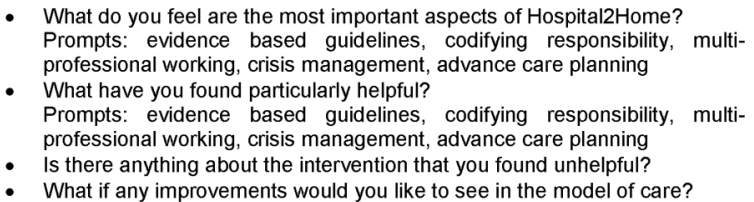

Figure 1 Topic guide used for qualitative interviews. and Hospital Anxiety and Depression scale (HADs) scores at 4 weeks were all sustained or continued to improve further by week 8 (see table 3). In contrast these indices did not significantly improve by week 4 for the waiting list group (and actually worsened for POS and KBILD questionnaire scores) but showed significant improvement once the intervention was delivered (ie, comparison weeks 4-8). There was also improvement in impact and total scores for St Georges Respiratory Questionnaire (SGRQ) scores in the fast-track group compared with the waiting list group. SGRQ scores for symptoms, impact and total scores also improved in the waiting list group once the intervention was delivered.

Positive effects were identified for patient HADs scores at week 4. This effect was sustained in the fast-track group with continued improvement. There was also improvement in the waiting list group for anxiety, depression, and total scores after the intervention was delivered.

There was no improvement in D12 scores in the fast-track group but there was an improvement in D12 scores between week 4 and week 8 in the waiting list group. There was no change in the Medical Research Council scores across both groups over time.

\section{Carer}

There was no significant difference in POS between the fasttrack and waiting lists groups at week 4 . However, there was a marked improvement in waiting list scores between week 4 and week 8 (18.0 (8.4) vs 13.7 (6.3)), respectively. Zarit Burden Inventory score and Carer Quality of Life Cancer burden, disruptiveness, financial and total scores followed a similar pattern with no effect of the intervention at week 4 . This was followed by improvement in scores between week 4 and week 8 in the waiting list group.

There were borderline effect sizes of the intervention on depression and total HADs scores $(-0.7(-1.3$ to 0.0$)$ and -0.7 $(-1.3$ to 0.0$)$, respectively). This was followed by improvement between week 4 and week 8 scores for the waiting list group for anxiety $(11.7(5.6)$ vs $9.8(4.6))$, depression $(9.6$ (4.9) vs 7.2 (3.9)) and total score (21.3 (9.9) vs $17.0(8.2))$, respectively.

Data related to study

As of study close on 31 December 2013, a greater number of waiting list patients $(13(54 \%))$ had died than fast-track (8 (32\%)). Preferred Place of Care and Preferred Place of Death were less likely to be achieved for patients who died in the waiting list group; Preferred Place of Care: fast-track (FT 8) (100\%) versus waiting list (WL) $11(84 \%)$, Preferred Place of Death: FT 7 (88\%) versus WL 10 (77\%). More patients died at home in the fast-track group; FT 5 (62\%) versus WL $5(38 \%)$ and in hospital in the waiting list group; FT $1(12 \%)$ versus WL 5 (38\%). All three patients who died before being able to receive the case conference were in the waiting list group and all died in hospital.

\section{Qualitative findings}

Online supplementary appendix 2 shows the qualitative participants' characteristics. Key quotes are presented in table 4 and the full qualitative findings can be found in online supplementary appendix 2 .

\section{DISCUSSION}

This fast-track randomised controlled trial of a case conference intervention in patients with advanced fibrotic ILD and carers identified an improvement in symptom control and quality of 


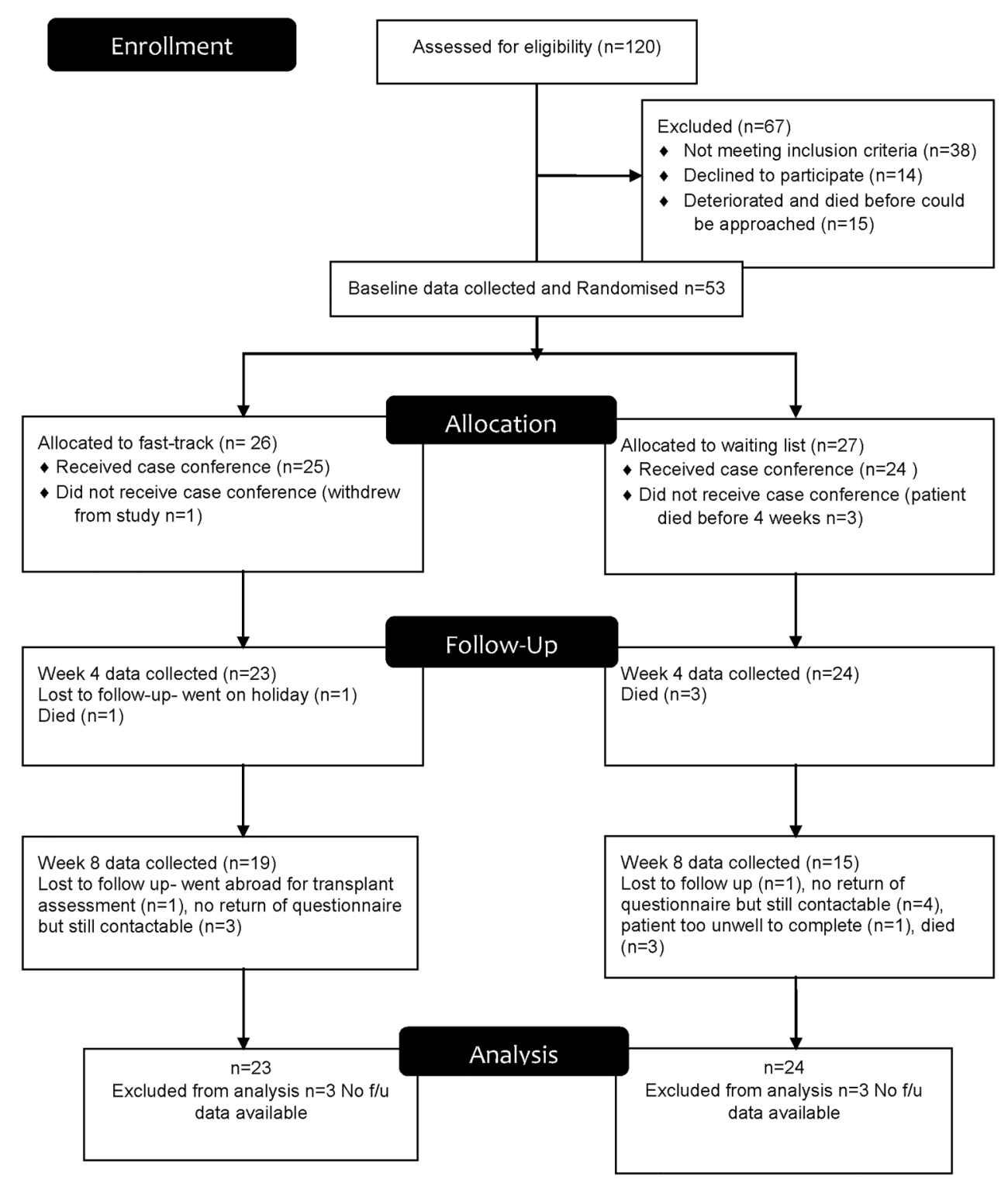

Figure 2 CONSORT diagram showing flow of patients through the study.

life. Of note, there was no worsening of any outcome after receiving the intervention. This suggests that no harm and potentially a prevention of deterioration may have occurred. Mean change difference scores in POS in the fast-track group were 5.7 points at 4 weeks, sustained at 8 weeks. For POS, a variation of one point in individual items is linked to clinical meaningful change. ${ }^{15}$ There was also a promising large effect size. Similar improvements in the waiting list POS once they received the intervention suggest that the intervention may improve the palliative care concerns of these patients. Use of evidence based guidelines and a comprehensive palliative care assessment at the case conference, ongoing palliative care involvement and/or added time with care providers may have contributed to this.

Baseline scores showed that patients were living with poor quality of life. Improvements were observed in the KBILD and SGRQ impact and total scores at week 4 in the fast-track group. The improvement in the waiting list SGRQ impact and total scores were marked between week 4 and week 8 where both domains showed improvement greater than the Minimal Important Clinical Difference for IPF. Improvements were also identified in anxiety and depression scores. Of note, baseline mean patient anxiety and depression scores and mean carer anxiety scores in both groups were borderline abnormal or abnormal. Importantly, the waiting list group showed deterioration for all anxiety and depression scores in the patients and carers during the 4 week wait. However, this improved after receiving the intervention. Clinically meaningful improvements in HADs scores of patients and their carers (the Minimal Important Clinical Difference in COPD is $1.5^{25}$ ) were identified. These improvements find correspondence with the qualitative interviews. Before the case conference, patients and carers stated they had very little knowledge of support they were entitled to and were suffering alone. Through the case conference, patients and carers had access to specialist community palliative care services that routinely support patients' and carers' holistic palliative care concerns. Patients and carers felt that this reduced anxiety. Moreover they were grateful for the clear crisis management strategy provided through the individualised care plan. Patients and carers interviewed valued the case conference itself as they felt that it 'laid everything on the table' and importantly addressed concerns and anxieties that had been playing on patients' and carers' minds. This supports findings by Lindell 
Table 2 Summary table of baseline demographic and clinical data

\begin{tabular}{|c|c|c|}
\hline Patients & $\begin{array}{l}\text { Fast-track } \\
\mathrm{N}=26\end{array}$ & $\begin{array}{l}\text { Waiting list } \\
\mathrm{N}=27\end{array}$ \\
\hline Age (years) & $67.1(10.9)$ & $70.6(10.3)$ \\
\hline Male & $20(77 \%)$ & $18(67 \%)$ \\
\hline \multicolumn{3}{|l|}{ Ethnicity } \\
\hline White UK & $21(81 \%)$ & $20(74 \%)$ \\
\hline Black or Black British & $1(4 \%)$ & $2(8 \%)$ \\
\hline Asian or Asian British & $4(15 \%)$ & $5(18 \%)$ \\
\hline \multicolumn{3}{|l|}{ Disease } \\
\hline IPF & $22(85 \%)$ & $22(82 \%)$ \\
\hline NSIP & $4(15 \%)$ & $5(18 \%)$ \\
\hline \multicolumn{3}{|l|}{ Diagnostic biopsy } \\
\hline Surgical & $8(31 \%)$ & $6(22 \%)$ \\
\hline Not carried out & $18(69 \%)$ & $21(78 \%)$ \\
\hline \multicolumn{3}{|l|}{$\%$ predicted TLCO } \\
\hline Mean (SD) & $25(10.7)$ & $23(5.8)$ \\
\hline Not carried out & $4(15 \%)$ & $4(15 \%)$ \\
\hline \multicolumn{3}{|l|}{ Extent of disease on CT } \\
\hline Limited $(<40 \%)$ & $3(12 \%)$ & $3(11 \%)$ \\
\hline Indeterminate (40-60\%) & $9(35 \%)$ & $14(52 \%)$ \\
\hline Extensive (>60\%) & $14(54 \%)$ & $10(37 \%)$ \\
\hline \multicolumn{3}{|l|}{ Extent of honeycombing on CT } \\
\hline Limited $(<15 \%)$ & $10(38 \%)$ & $11(41 \%)$ \\
\hline Indeterminate (15-35\%) & $11(42 \%)$ & $10(37 \%)$ \\
\hline Extensive (>35\%) & $5(19 \%)$ & $6(22 \%)$ \\
\hline \multicolumn{3}{|l|}{ Composite Physiological Index } \\
\hline$>50$ & $19(73 \%)$ & $27(100 \%)$ \\
\hline Mean (SD) & $66.5(4.0)$ & $64.8(3.6)$ \\
\hline Not carried out & $7(27 \%)^{*}$ & 0 \\
\hline \multicolumn{3}{|l|}{ Using oxygen } \\
\hline Yes & $20(77 \%)$ & $23(85 \%)$ \\
\hline Litres/h used & $3(1.4)$ & $3(1.1)$ \\
\hline Usage in $24 \mathrm{~h}$ & $19(6.6)$ & $21(5.3)$ \\
\hline \multicolumn{3}{|l|}{ Comorbidities } \\
\hline Yes & $17(65 \%)$ & $13(48 \%)$ \\
\hline Heart failure & 1 & 0 \\
\hline COPD & 4 & 1 \\
\hline Pulmonary embolism & 1 & 0 \\
\hline TB & 0 & 0 \\
\hline Cancer & 1 & 1 \\
\hline Diabetes & 5 & 4 \\
\hline Other & 13 & 10 \\
\hline Carers & $\mathrm{N}=19$ & $\mathrm{~N}=26$ \\
\hline Age & $61.3(14.0)$ & $60.3(13.1)$ \\
\hline Male & $6(32 \%)$ & $6(23 \%)$ \\
\hline \multicolumn{3}{|l|}{ Ethnicity } \\
\hline White UK & $17(90 \%)$ & $18(69 \%)$ \\
\hline Black or Black British & $1(5 \%)$ & $2(8 \%)$ \\
\hline Asian or Asian British & $1(5 \%)$ & $6(23 \%)$ \\
\hline \multicolumn{3}{|c|}{$\begin{array}{l}\text { Data are means (SD) or numbers (\%). } \\
\text { *Three patients were recruited who had end-stage disease clinically, did not have } \\
\text { extensive disease or honeycombing on CT and were too unwell to complete lung } \\
\text { function tests. } \\
\text { IPF, idiopathic pulmonary fibrosis; NSIP, Non-specific interstitial pneumonia; } \\
\text { TLCO, carbon monoxide transfer factor. }\end{array}$} \\
\hline
\end{tabular}

et al who evaluated an interventional disease management programme in IPF and Higginson et al's ${ }^{26}$ recent trial of a breathlessness intervention service among 105 patients with refractory breathlessness (including patients with ILD). Both observed improvements in psychological symptoms.

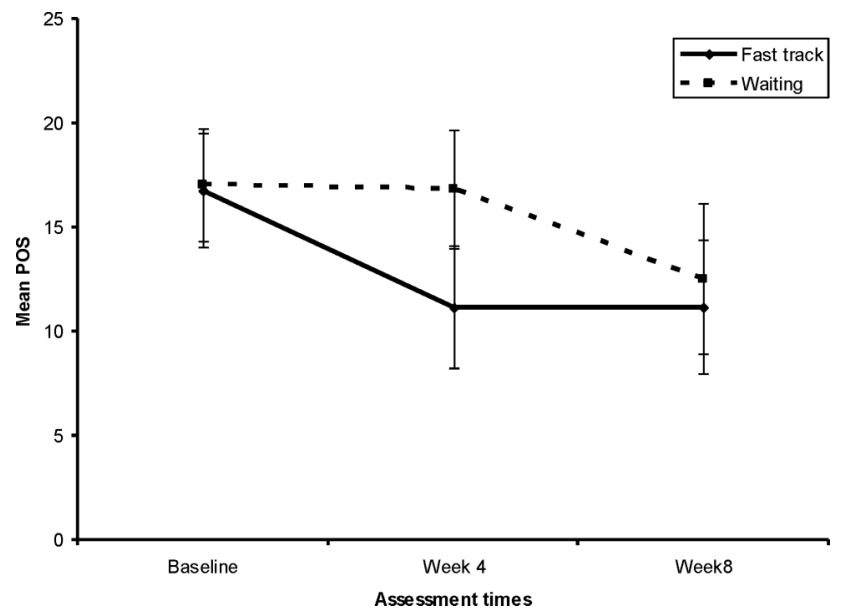

Figure 3 Line diagram showing change in mean Palliative Care Outcome Scale (POS) with $95 \%$ Cls over time in the two groups.

Hospital2Home aimed to facilitate early discussion about disease progression, to improve communication and address end-of-life planning needs. Not all patients wanted to talk about advance care planning decisions such as preferred place of care and preferred place of death. This was similarly identified by Abernethy et $a l^{10}$ where prognosis, end-of-life issues, and previous experiences of death were rarely discussed at the case conference for patients with cancer. For those patients in this trial who did discuss advance care planning, even though it could initially be distressing for relatives, it was seen as incredibly useful. For some patients, the case conference provided them with permission to conduct these important conversations. Interestingly, patients who did not want to discuss advance care planning at the case conference then went on to have subsequent discussions with their community health professionals. This may have been precipitated by those initial discussions by the Hospital2Home nurse and the development of relationships with the community palliative care team after the case conference. For patients who wished to discuss preferred place of death, no patients reported hospital as their preference. The actual place of death for patients having received the case conference was hospital in only $28 \%$ of patients. This is much less than observed in a retrospective case note review ${ }^{2}$ where $76 \%$ of patients with advanced fibrotic ILD attending two acute hospitals died in hospital. Interestingly, the three patients who died in the waiting list group before receiving the intervention, died in hospital. Patients with IPF experience increased healthcare resource utilisation, and direct medical costs. ${ }^{27}$ This is important at the end of life. It is possible that the case conference, through documenting end-of-life preferences, establishing links in the community setting, and preventing crisis admissions enabled patients not to die in hospital. The economic impact of this requires further investigation.

The fast-track study design worked effectively and is likely to be an influencing factor as to why consent and recruitment rates were met as all patients received the intervention. However, only $24 \%$ of the fast-track group received the case conference within the a priori 14-day allotted time frame. Health professionals were often unable to schedule a case conference within a week's notice. This has been found previously; Abernethy et $a l^{10}$ observed that only 38/167 case conferences in their trial were held within 28 days. When considering the waiting list period, 4 weeks was chosen as this was considered long enough to identify an effect of the intervention on the primary 
Table 3 Outcome measure data: outcome data for completed (fully or partially) measures have been presented

\begin{tabular}{|c|c|c|c|c|c|c|c|c|c|}
\hline & \multicolumn{4}{|l|}{ Fast track } & \multicolumn{4}{|l|}{ Waiting list } & \multirow[b]{2}{*}{$\begin{array}{l}\text { Effect size }(95 \% \mathrm{Cl}) \text { at } \\
4 \text { weeks }\end{array}$} \\
\hline & $\begin{array}{l}\text { Baseline (mean (SD) } \\
\text { or } n(\%)\end{array}$ & $\begin{array}{l}4 \text { weeks (mean (SD) } \\
\text { or } n(\%)\end{array}$ & $\begin{array}{l}\text { Change } \\
\text { score } \\
\text { Mean (SD) }\end{array}$ & $\begin{array}{l}8 \text { week (mean (SD) } \\
\text { or } \mathrm{n}(\%)\end{array}$ & $\begin{array}{l}\text { Baseline (mean (SD) } \\
\text { or } \mathrm{n}(\%)\end{array}$ & $\begin{array}{l}4 \text { weeks (mean (SD) } \\
\text { or } n(\%)\end{array}$ & $\begin{array}{l}\text { Change } \\
\text { score } \\
\text { Mean (SD) }\end{array}$ & $\begin{array}{l}8 \text { week (mean (SD) } \\
\text { or } n(\%)\end{array}$ & \\
\hline $\begin{array}{l}\text { Primary end } \\
\text { point }\end{array}$ & $\mathrm{N}=26$ & $\mathrm{~N}=23$ & & & $\mathrm{~N}=27$ & $N=24$ & & & \\
\hline \multirow[t]{2}{*}{ POS } & $16.8(5.6)$ & $11.2(7.9)$ & $-5.7(7.5)$ & & $17.0(6.3)$ & $16.8(8.9)$ & $-0.4(8.0)$ & & $-0.7(-1.2$ to -0.1$)$ \\
\hline & \multicolumn{8}{|c|}{ The mean change difference between the two arms was $-5.3(95 \% \mathrm{Cl}:-9.8$ to -0.7$)$ Independent $\mathrm{t}$ test $\mathrm{p}=0.02$} & \\
\hline \multicolumn{10}{|c|}{ Secondary outcomes } \\
\hline \multicolumn{10}{|c|}{ Patients } \\
\hline \multirow[t]{2}{*}{ POS } & & & & $\mathrm{N}=19$ & & & & $\mathrm{~N}=15$ & \\
\hline & & & & $11.2(7.3)$ & & & & $12.5(6.6)$ & \\
\hline \multirow[t]{2}{*}{ D12 } & $\mathrm{N}=25^{*}$ & $\mathrm{~N}=22^{*}$ & & $N=19$ & $\mathrm{~N}=27$ & $\mathrm{~N}=24$ & & $\mathrm{~N}=15$ & \\
\hline & $22.8(8.7)$ & $21.6(10.1)$ & $-0.8(7.2)$ & $20.4(9.8)$ & $25.9(8.2)$ & $25.0(10.7)$ & $-0.6(21.3)$ & $21.3(10.5)$ & $-0.3(-0.9$ to 0.3$)$ \\
\hline \multirow[t]{2}{*}{ KBILD† } & $\mathrm{N}=26$ & $\mathrm{~N}=23$ & & $\mathrm{~N}=19$ & $\mathrm{~N}=27$ & $\mathrm{~N}=24$ & & $\mathrm{~N}=15$ & \\
\hline & $35.8(13.0)$ & $40.0(16.2)$ & $3.5(11.0)$ & $43.2(18.4)$ & $32.3(12.9)$ & $30.3(16.2)$ & $-2.6(21.3)$ & $34.9(18.0)$ & 0.6 (0.0 to 1.2$)$ \\
\hline SGRQ & $\mathrm{N}=25 \ddagger$ & $\mathrm{N}=22 \ddagger$ & & $\mathrm{N}=18 \ddagger$ & $\mathrm{N}=26 \S$ & $\mathrm{N}=24$ & & $\mathrm{~N}=15$ & \\
\hline Symptoms & $62.2(17.7)$ & $62.0(20.5)$ & $1.4(16.5)$ & $52(20.1)$ & $66.3(24.5)$ & $65.8(23.0)$ & $-2.0(23.7)$ & $60.2(23.8)$ & $-0.2(-0.8$ to 0.4$)$ \\
\hline Impact & $61.6(18.0)$ & $56.3(20.3)$ & $-4.0(19.7)$ & $57.4(20.8)$ & $71.4(12.8)$ & $74.8(14.9)$ & $2.8(13.3)$ & $62.3(13.5)$ & $-1.0(-1.6$ to -0.4$)$ \\
\hline Total & $70.0(13.0)$ & $66.0(16.4)$ & $-2.8(14.9)$ & $65.7(14.7)$ & $76.8(10.1)$ & $78.6(11.8)$ & $0.7(10.5)$ & $70.8(10.8)$ & $-0.9(-1.5$ to -0.3$)$ \\
\hline MRC & $\mathrm{N}=26$ & $\mathrm{~N}=23$ & & $\mathrm{~N}=19$ & $\mathrm{~N}=27$ & $\mathrm{~N}=24$ & & $\mathrm{~N}=15$ & \\
\hline Median & 4 & 4 & & 4 & 5 & 5 & & 4 & \\
\hline IQR (25-75) & $4-5$ & $4-5$ & & $4-5$ & $4-5$ & $4-5$ & & $4-5$ & \\
\hline HADs & $\mathrm{N}=26$ & $\mathrm{~N}=23$ & & $\mathrm{~N}=19$ & $\mathrm{~N}=27$ & $\mathrm{~N}=24$ & & $\mathrm{~N}=15$ & \\
\hline Anxiety & $9.6(4.6)$ & $8.1(4.1)$ & $-1.7(3.3)$ & $7.1(4.6)$ & $9.7(5.7)$ & $10.8(5.5)$ & $1.2(4.8)$ & $7.9(5.5)$ & $-0.6(-1.1$ to 0.0$)$ \\
\hline Depression & $9.0(3.1)$ & $9.4(3.0)$ & $0.3(3.2)$ & $8.3(3.7)$ & $11.0(4.7)$ & $12.3(4.8)$ & $1.5(4.12)$ & $9.3(4.5)$ & $-0.7(-1.3$ to -0.1$)$ \\
\hline Total score & $18.6(6.4)$ & $17.5(6.3)$ & $-1.4(5.0)$ & $15.4(7.7)$ & $20.7(9.0)$ & $23.0(9.7)$ & $2.8(8.1)$ & $17.2(9.4)$ & $-0.7(-1.2$ to -0.1$)$ \\
\hline \multicolumn{10}{|l|}{ Carers } \\
\hline \multirow[t]{2}{*}{ POS } & $\mathrm{N}=19$ & $\mathrm{~N}=15$ & & $\mathrm{~N}=13$ & $\mathrm{~N}=26$ & $\mathrm{~N}=22$ & & $\mathrm{~N}=15$ & \\
\hline & $17.8(6.5)$ & $14.7(6.5)$ & $-2.9(5.8)$ & $16.1(6.9)$ & $18.5(6.2)$ & $18.0(8.4)$ & $-0.7(9.6)$ & $13.7(6.3)$ & $-0.4(-1.1$ to 0.2$)$ \\
\hline \multirow[t]{2}{*}{ ZBI } & $\mathrm{N}=19$ & $\mathrm{~N}=16$ & & $\mathrm{~N}=13$ & $\mathrm{~N}=26$ & $\mathrm{~N}=23$ & & $\mathrm{~N}=16$ & \\
\hline & $22.2(15.2)$ & $22.3(15.3)$ & $0.1(0.2)$ & $26.2(13.4)$ & $32.2(11.7)$ & $31.7(17.3)$ & $-0.1(0.3)$ & $25.4(13.4)$ & $-0.6(-1.2$ to 0.1$)$ \\
\hline HADs & $\mathrm{N}=19$ & $\mathrm{~N}=16$ & & $\mathrm{~N}=13$ & $\mathrm{~N}=26$ & $\mathrm{~N}=23$ & & $\mathrm{~N}=16$ & \\
\hline Anxiety & $9.3(4.3)$ & $8.8(4.8)$ & $-0.5(4.8)$ & $9.2(3.7)$ & $11.0(5.9)$ & $11.7(5.6)$ & $0.6(5.3)$ & $9.8(4.6)$ & $-0.6(-1.2$ to 0.1$)$ \\
\hline Depression & $7.0(4.9)$ & $6.4(4.1)$ & $-0.3(3.5)$ & $7.0(4.2)$ & $8.7(5.0)$ & $9.6(4.9)$ & $1.0(4.6)$ & $7.2(3.9)$ & $-0.7(-1.3$ to 0.0$)$ \\
\hline Burden & $7.8(6.0)$ & $7.1(6.9)$ & $-0.6(4.3)$ & $7.7(4.8)$ & $9.6(5.4)$ & $9.3(5.5)$ & $0.0(4.9)$ & $7.6(5.9)$ & $-0.4(-1.0$ to 0.3$)$ \\
\hline
\end{tabular}




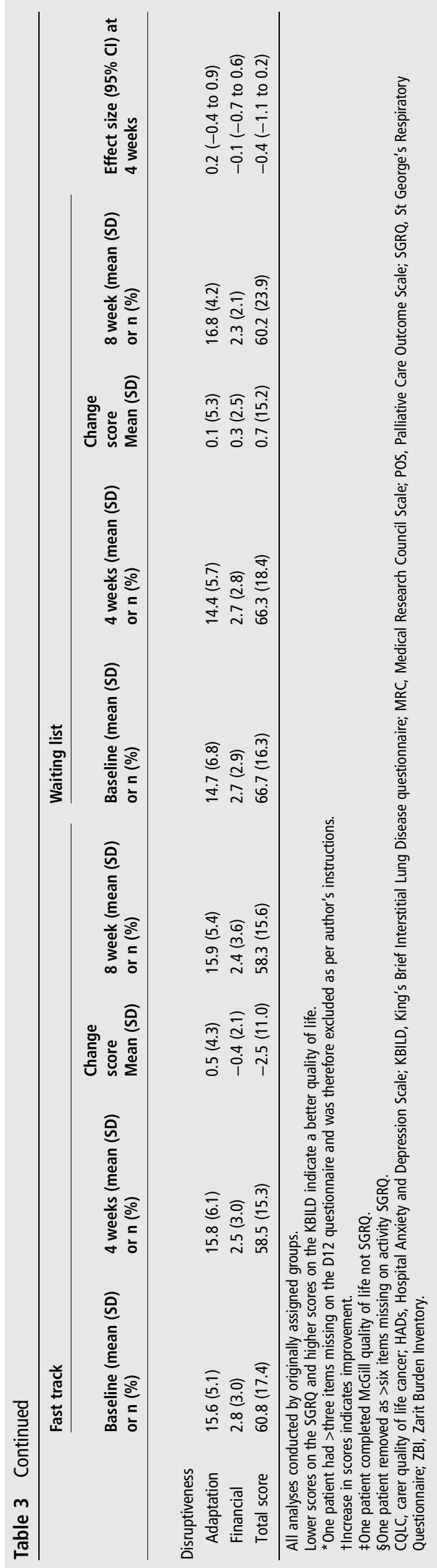

outcome, but not result in a high rate of attrition due to death. However, as only a small number of patients (3/27) did not receive the case conference intervention as they died before 4 weeks, this time period could be extended in any future phase III study allowing health professionals in the fast-track group adequate advance notice to attend a case conference.

Patients, carers and health professionals alike praised the Hospital2Home model of care. General practitioners have previously reported that a case conference allows them to be better informed, makes discharge planning easier and gives clear delineation of the role between primary care and specialist services, ${ }^{28}$ findings supported by this trial. However, compared with patients with cancer, fewer general practitioners attended the case conferences (less than a third in the fast-track and less than $50 \%$ in the waiting list group; $100 \%$ for patients with cancer). Further, in some instances community palliative care declined referrals despite clear explanations of the nature of the study and patients' palliative care needs. This is likely to reflect the lack of understanding among community health professionals of the terminal nature of advanced idiopathic fibrotic lung diseases and their associated palliative care needs. This requires ongoing education. The qualitative work also identified lack of early referral to palliative care by community health professionals, despite requests from patients and carers, and some gatekeeping by hospital health professionals. It is clear that there is still a misconception that palliative care is a last resort and referral should only be made at the end of life. This exists in spite of WHO's advice that palliative care should be delivered in parallel to active care once a life-limiting illness has been identified. Recommendations of the British Thoracic Society ${ }^{29}$ and the National Institute for Health and Care Excellence ${ }^{30}$ support this; palliative care teams should be involved in management of patients with IPF to ensure adequate symptom control and psychological support. If palliative care is only delivered at the end of life, patients and carers may be denied valuable symptom control and psychosocial support in earlier stages of the disease and important decisions around end-of-life preferences may not be identified and acted upon. Strategies on improving the knowledge of patients, carers and health professionals on the benefits of early palliative care need to be explored.

The recent National Institute for Health and Care Excellence guidance for IPF has stated that the ILD specialist services ought to able to manage the palliative care needs of patients and to refer to the appropriate community services. ${ }^{30}$ In addition, only patients whose palliative care concerns cannot be met by the ILD services ought be referred to specialist palliative care services. ${ }^{30}$ However, despite involvement of specialist ILD services, patients and carers continue to have unmet palliative care concerns and limited community support. ${ }^{3}$ In reality, the pressure of busy ILD clinics is likely to mean that concerns are not assessed and remain neglected. Hospital2Home may enable these concerns to be examined and managed through an individualised care plan while facilitating development of important relationships with community health professionals.

There are a number of limitations to this trial. POS has not been validated in ILD, however, nor have other holistic palliative care measures. This phase II trial was not adequately powered to identify efficacy, therefore results must be interpreted with caution. Despite this the trend towards positive differences between groups was observed and strongly suggests a further adequately powered study that is informed by the learning from this study. Referrals to community services for the waiting list group were made at randomisation and beyond the control of the study, a few community services contacted 
Table 4 Presentation of qualitative findings (all names have been changed to ensure confidentiality)

\begin{tabular}{|c|c|c|}
\hline Theme & Participant & Example quote \\
\hline Support in the community & $\begin{array}{l}\text { Ann, 72-year-old wife of Stephen } \\
\text { who had advanced NSIP }\end{array}$ & $\begin{array}{l}\text { "I was bit nervous before hand you didn't have anyone to turn to really..... we have one son in } \\
\text { xxxx but he's far away and ( } 2 \text { ) I have a sister in xxxx which phones me up every day but [coughs] } \\
\text { otherwise that's I felt alon:.:." "and how do you feel now?" (SB)"I feel better....... "cause I have } \\
\text { all the phone numbers and people phone me up...." }\end{array}$ \\
\hline $\begin{array}{l}\text { Individual care plans and practical } \\
\text { problems addressed }\end{array}$ & Community palliative care CNS & $\begin{array}{l}\text { "[the } \mathrm{H} 2 \mathrm{H} \text { CNS] contacted us afterwards to check everything we had said we were going to do } \\
\text { we'd done which we had erm::: and we had her number to be able to contact if he had any } \\
\text { problems as well so::.: erm it went all quite smoothly really..." }\end{array}$ \\
\hline $\begin{array}{l}\text { Coordination of care and } \\
\text { efficiency }\end{array}$ & GP & $\begin{array}{l}\text { "if it wasn't for this (2) I can see a completely different scenario where this guy would be lost in } \\
\text { the community ....he::.: would be trying to find out who::.: the respiratory nurse is [laughs] trying } \\
\text { to get out who's the oxygen supplier trying to find out from his GP which one's going to be in } \\
\text { charge of his care in the general practice which one's going to be helping him with his symptoms } \\
\text { (1) you know it it would have become a hug:::e hassle and I don't think he:.: realises how lucky } \\
\text { he is actually to be part of this trial (2) because everything's there for him (2) there's no other } \\
\text { issue..." }\end{array}$ \\
\hline Crisis management & $\begin{array}{l}\text { Peter, 63-year-old with advanced } \\
\text { IPF }\end{array}$ & $\begin{array}{l}\text { "and now I've got all erm (2) they as I say they phone and I've got er a whole list of numbers } \\
\text { that I can phone any time day or night erm if I need to, you know....oh yes yeah and (1) and (2) } \\
\text { as I say I've got erm the telephone numbers... of of people that I can phone erm } 24 \text { seven which } \\
\text { is ideal I mean before that erm the most I could do was dial 999" }\end{array}$ \\
\hline $\begin{array}{l}\text { Palliative care, psychological } \\
\text { support }\end{array}$ & $\begin{array}{l}\text { Ted, 55-year-old patient with } \\
\text { advanced IPF }\end{array}$ & $\begin{array}{l}\text { "I must say to everybody (2) definitely it is it it's (2) I don't know how long I've got left but (2) } \\
\text { whatever time I've got left ( } 3 \text { ) this palliative care is going to make that time better for me and } \\
\text { it's better and if it's better for me it's better ( } 2 \text { ) for us as a family....I've been telling everybody } \\
\text { (2) how important ( } 3 \text { ) you know I just wish I could get GPs in to buy into the (2) palliative care } \\
\text { cause its makes such a difference (2) made such a difference to me...... I have weeks when ( } 2 \text { ) } \\
\text { er like last week I wanted to talk about (3) you know (2) my illness and stuff... and they're there } \\
\text { then ( } 2 \text { ) for me to be able to tap into.. which I am happy for because (3) when you're in in my } \\
\text { my sort of position when you know your life limited (1) is your life is limited often at home (3) } \\
\text { you tend you live a lie say to people you live a lie I think because say how do you feel you just } \\
\text { say I feel fine but because you don't want to be worrying people all the time but (1) when } \\
\text { you've got a palliative care team round you you can get that out of your system which is } \\
\text { something we didn't have for the first } 18 \text { months two years of this disease" }\end{array}$ \\
\hline Symptom control & ILD Consultant & $\begin{array}{l}\text { "We would star:::t er symptom control in hospital whether that was a little bit of Oramor:::.ph or } \\
\text { lorazep:::am and then it was really we wouldn't often see the patient for another } 3 \text { or } 4 \text { months } \\
\text { time and it was then back to the GPs han::::ds to sort of titrate and change that as needed um } \\
\text { and it it didn't always go successfully the things weren't re-prescrib:::ed or wrong doses were } \\
\text { given but knowing that er (1) you and your team are now doing that again we've had patients } \\
\text { say that it's been very useful for them to have sort of continuity of care and someone taking } \\
\text { overall view of that...." }\end{array}$ \\
\hline Empowering HP & ILD CNS & $\begin{array}{l}\text { "It's certainly enhanced my practice, um, certainly there's an huge (1) element of my job which is } \\
\text { dealing with um the palliative care and end of life of patients, and I think, seeing how palliative } \\
\text { care interact with patients and bring up (1) uncomfortable::.: (2) subjects for us as healthcare } \\
\text { professionals, certainly has enhanced my practice.... We need to:.: (1) understand that these } \\
\text { aren't necessarily subjects that patients don't want to discuss... sometimes some of the anxiety } \\
\text { around the issues can be discussing what the future is, discussing, (1) you know, having those } \\
\text { uncomfortable conversations. I think, H2H has facilitated that, helped patients be more organised } \\
\text { and think around what they're doing and also highlighted to us how to go about those } \\
\text { conversations, and that those conversations are (1) ok to have." }\end{array}$ \\
\hline Advance care planning & $\begin{array}{l}\text { Leslie, 54-year-old wife of Ted who } \\
\text { had advanced IPF }\end{array}$ & $\begin{array}{l}\text { "For us it was a bit traumatic you know everything being coming to life that actually these things } \\
\text { are happening I think you can go to hospital appointments and still sort of brush it aside that } \\
\text { you know [laughs] erm (2) but once everybody was sat round the table and we talked about } \\
\text { DNRs ... and erm (4) advanced directives and all this sort of stuff it did bring it home and it did } \\
\text { get a little bit (3) upsetting but (3) I I still do believe that it was better at that point than when } \\
\text { (1) somebody's actual laid on their bed and you think it could be any da::.:y and (2) erm (1) you } \\
\text { know I think you can deal with it better at that stage" }\end{array}$ \\
\hline
\end{tabular}

CNS, Clinical nurse specialist; DNR, Do not resuscitate; GP, General practitioner; H2H, Hospital2Home; HP, Health professional; ILD, interstitial lung disease; IPF, idiopathic pulmonary fibrosis; NSIP, Non-specific interstitial pneumonia.

patients and carers before the case conference. This coupled with the delay in delivering the case conference to the fast-track group may have affected comparison of the efficacy of the intervention at the primary end point of 4 weeks. However, these factors are likely to have underestimated rather than overestimated any effect. The high resolution computed tomography/ composite physiologic index criteria for excluded patients were not recorded which may have provided valuable clinical information. The Hospital2Home intervention is a complex intervention with multiple different components. Attempts were made to standardise delivery as much as possible with pro forma and evidence based guidelines. Despite this, there is likely to have been some variance in delivery. Due to constraints of the study, outcome measures were not collected after the 8 week mark. This may have provided valuable information of possible effects of the intervention over time.

\section{CONCLUSION}

Preliminary evidence from this trial reveals a positive effect on patients and carers of the Hospital2Home intervention on palliative care concerns, quality of life and anxiety and depression. In addition, the intervention managed uncertainty by facilitating 
early discussion about disease progression, improving communication and addressing end-of-life planning needs. The Hospital2Home intervention therefore appears to be feasible, acceptable and effective across a number of domains.

As this is a phase II study, any positive effects may be promising but would need to be further examined in a multicentre phase III study before conclusions about wider effectiveness may be drawn. However, the information obtained from this trial will allow sample size calculation in future studies. In addition, this study has provided valuable information about the patients and carers affected by advanced idiopathic fibrotic ILDs as well as the potential effects of the Hospital2Home intervention in this group.

Acknowledgements The authors thank Philippa Johnston for qualitative transcription.

Contributors JRR conceived the study and secured funding. SB, JRR, AUW, KM, SSB, ASP, IJH and JR contributed to the design of the study. SB and CO conducted the study. JRR supported the day-to-day running of the study. SB completed all quantitative and qualitative analyses. KM supported all quantitative analysis. JK supported all qualitative analysis. SB drafted the paper. JRR, AUW, KM, CO, SSB, $A S P, J K$ and IJH edited and revised the paper critically for important intellectual content. SB, JRR, AUW, KM, CO, SSB, ASP, JK, IJH and JR approved the final version to be published.

Funding This study was funded partly by a grant from Marie Curie which paid for the Hospital2Home CNS. Marie Curie had no input into the analysis of data or drafting of the manuscript. The remainder of the funding was from the Royal Marsden and Royal Brompton Palliative Care Research Fund which is funded from charitable sources. IJH is a NIHR senior investigator.

Competing interests None declared.

Ethics approval National Research Ethics Service Committee London-Chelsea (ref number:11/L0/0999).

Provenance and peer review Not commissioned; externally peer reviewed.

\section{REFERENCES}

1 Hubbard R, Johnston I, Britton J. Survival in patients with cryptogenic fibrosing alveolitis: a population-based cohort study. Chest 1998;113:396-400.

2 Bajwah S, Higginson IJ, Ross JR, et al. Specialist palliative care is more than drugs: a retrospective study of ILD patients. Lung 2012;190:215-20.

3 Bajwah S, Higginson IJ, Ross JR, et al. The palliative care needs for fibrotic interstitial lung disease: a qualitative study of patients, informal caregivers and health professionals. Palliat Med 2013;27:869-76.

4 Baiwah S, Koffman J, Higginson IJ, et al. 'I wish I knew more ...' the end-of-life planning and information needs for end-stage fibrotic interstitial lung disease: views of patients, carers and health professionals. BMJ Support Palliat Care 2013;3:84-90.

5 Health and Social Care Act. London: Department of Health, 2012.

6 Health Do. NHS Future Forum: recommendations to government on NHS modernisation. London: Department of Health, 2011.

7 Brazil K, Bainbridge D, Sussman J, et al. Coordination of palliative cancer care in the community: "unfinished business". Support Care Cancer 2009;17:819-28.

8 Abernethy AP, Currow DC, Hunt $R$, et al. A pragmatic $2 \times 2 \times 2$ factorial cluster randomized controlled trial of educational outreach visiting and case conferencing in palliative care-methodology of the Palliative Care Trial [ISRCTN 81117481]. Contemp Clin Trials 2006:27:83-100.

9 Mitchell GK, Del Mar CB, O'Rourke PK, et al. Do case conferences between general practitioners and specialist palliative care services improve quality of life? A randomised controlled trial (ISRCTN 52269003). Palliat Med 2008;22:904-12.
10 Abernethy AP, Currow DC, Shelby-James T, et al. Delivery strategies to optimize resource utilization and performance status for patients with advanced life-limiting illness: results from the "palliative care trial" [ISRCTN 81117481]. J Pain Symptom Manage 2013:45:488-505

11 Bajwah S, Ross JR, Peacock JL, et al. Interventions to improve symptoms and quality of life of patients with fibrotic interstitial lung disease: a systematic review of the literature. Thorax 2013;68:867-79.

12 Medical Research Council. Developing and evaluating complex interventions: new guidance, 2008

13 [No authors listed]. American Thoracic Society. Idiopathic pulmonary fibrosis: diagnosis and treatment. International consensus statement. American Thoracic Society (ATS), and the European Respiratory Society (ERS). Am J Respir Crit Care Med 2000:161(2 Pt 1):646-64.

14 Well AU, Hansell DM, Barker R, et al. A simple prognostic staging system for idiopathic fibrosing lung disease. The Fleischner Society Annual Meeting. Cleveland, Ohio, 2010

15 Hearn J, Higginson IJ. Development and validation of a core outcome measure for palliative care: the palliative care outcome scale. Palliative Care Core Audit Project Advisory Group. QualHealth Care 1999:8:219-27.

16 Swigris JJ, Yorke J, Sprunger DB, et al. Assessing dyspnea and its impact on patients with connective tissue disease-related interstitial lung disease. Respir Med 2010;104:1350-5.

17 Patel AS, Siegert RJ, Brignall K, et al. The development and validation of the King's Brief Interstitial Lung Disease (K-BILD) health status questionnaire. Thorax 2012;67:804-10

18 Swigris JJ, Brown KK, Behr J, et al. The SF-36 and SGRQ: validity and first look at minimum important differences in IPF. Respir Med 2010;104: 296-304

19 Mahler DA, Wells CK. Evaluation of clinical methods for rating dyspnea. Chest 1988:93:580-6.

20 Zigmond AS, Snaith RP. The hospital anxiety and depression scale. Acta Psychiatr Scand 1983;67:361-70.

21 Weitzner MA, Jacobsen PB, Wagner $\mathrm{H} \mathrm{Jr}$, et al. The Caregiver Quality of Life Index-Cancer (CQOLC) scale: development and validation of an instrument to measure quality of life of the family caregiver of patients with cancer. Quallife Res 1999:8:55-63.

22 Novak M, Guest C. Application of a multidimensional caregiver burden inventory. Gerontologist 1989;29:798-803.

23 Strauss A, Corbin J. Basics of qualitative research: techniques and procedures for developing grounded theory. Thousand Oaks, CA: Sage, 1998.

24 Critchley P, Plach N, Grantham M, et al. Efficacy of haloperidol in the treatment of nausea and vomiting in the palliative patient: a systematic review. J Pain Symptom Manage 2001;22:631-4.

25 Puhan MA, Frey M, Buchi S, et al. The minimal important difference of the hospital anxiety and depression scale in patients with chronic obstructive pulmonary disease. Health Qual Life Outcomes 2008:6:46.

26 Higginson IJ, Bausewein C, Reilly CC, et al. An integrated palliative and respiratory care service for patients with advanced disease and refractory breathlessness: a randomised controlled trial. Lancet Respir Med 2014;2:979-87.

27 Collard HR, Ward AJ, Lanes $\mathrm{S}$, et al. Burden of illness in idiopathic pulmonary fibrosis. J Med Econ 2012;15:829-35.

28 Mitchell G, Cherry M, Kennedy R, et al. General practitioner, specialist providers case conferences in palliative care-lessons learned from 56 case conferences. Aust Fam Physician 2005;34:389-92.

29 Bradley B, Branley HM, Egan JJ, et al., British Thoracic Society Interstitial Lung Disease Guideline Group, British Thoracic Society Standards of Care Committee; Thoracic Society of Australia; New Zealand Thoracic Society; Irish Thoracic Society. Interstitial lung disease guideline: the British Thoracic Society in collaboration with the Thoracic Society of Australia and New Zealand and the Irish Thoracic Society. Thorax 2008;63(Suppl 5):v1-58

30 Excellence NIfHaC. Diagnosis and managment of suspected idiopathic pulmonary fibrosis. National Clinical Guideline Centre, 2013. 